\title{
THE VALENCE OF NITROGEN IN AMMONIUM SALTS.
}

\author{
By WILLIAM A. NOYES AND RALPH S. POTTER.
}

\section{(Read April 24, I9I4.)}

During the early years of the development of the theory of valence many chemists held the view that each element has an unvarying valence. The apparent change of valence in nitrogen from ammonia to ammonium salts and in phosphorus from phosphorus trichloride to phosphorus pentachloride was explained by calling the ammonium salts and the pentachloride molecular compounds, as distinguished from ammonia and the trichloride, in which the true valence of the elements was supposed to be shown. This view received support from the dissociation of ammonium salts and of phosphorus pentachloride in the gaseous state. Gradually, with the demonstration that phosphorus pentachloride volatilizes in part unchanged, that phosphorus pentafluoride, $\mathrm{PF}_{5}$, has a vapor density corresponding to its formula and, in general, that dissociation in the gaseous state does not correspond to any rational distinction between unitary and molecular compounds the view that elements may show a varying valence in their compounds and that nitrogen and phosphorus are sometimes trivalent and sometimes quinquivalent, came to be generally accepted.

More recently Werner $^{1}$ has proposed a modified molecular formula for ammonium chloride, $\mathrm{H}_{3} \mathrm{~N}$. $\mathrm{HCl}$. By this formula he intends to indicate that in the ammonium salts the nitrogen atom retains a normal valence of three but that the nitrogen atom of the ammonia and the hydrogen atom of the hydrochloric acid are held together by secondary ("Neben") valences, the hydrogen and chlorine of the acid retaining essentially the same relation to each other as in the free acid.

${ }^{1}$ See "Neuere Anschauungen auf dem Gebiet der anorganischen Chemie," p. 96 ( 1905$)$. 
An amino acid may, theoretically, assume in the aqueous solu-

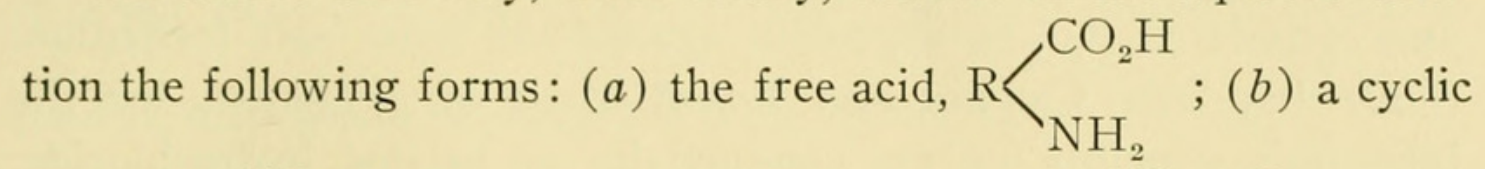
salt, $\mathrm{R}\left\langle\begin{array}{c}\mathrm{CO} \\ \mathrm{NH}_{3}\end{array}\right\rangle \mathrm{O}$, wr according to Werner, $\mathrm{R}\left\langle\begin{array}{c}\mathrm{CO}-\mathrm{O} \\ \vdots \\ \mathrm{NH}_{2}-\mathrm{H}\end{array} ;(\right.$ c $)$ a bimolecular or polymolecular salt formed by the union of two or more molecules, $\mathrm{R}\left\langle\begin{array}{c}\mathrm{CO}_{2}-\mathrm{H}_{3} \mathrm{~N} \\ \mathrm{NH}_{3}-\mathrm{O}_{2} \mathrm{C}\end{array}\right\rangle \mathrm{R} ;(d)$ the ions of the acid group, $\mathrm{R}\left\langle{ }_{\mathrm{NH}_{2}}^{\mathrm{CO}_{2}^{-}}\right.$and $\mathrm{H}^{+} ;(e)$ the ions of the base, $\mathrm{R}\left\langle{ }_{\mathrm{NH}_{3}{ }^{+}}^{\mathrm{CO}_{2} \mathrm{H}}\right.$ and $\mathrm{OH}^{-} ;(f)$ the double, amphoteric ion, $\mathrm{R}\left\langle\mathrm{NH}_{3}^{+}{ }^{{ }^{+}} \mathrm{CO}^{-}\right.$

The "inner salt" structure was first proposed by Erlenmeyer and Siege $1^{3}$ in 1875 . Ten years later Ostwald ${ }^{4}$ noticed that solutions of glycocoll, $\mathrm{CH}_{2} \mathrm{NH}_{2} \mathrm{CO}_{2} \mathrm{H}$, have a very low molecular conductivity and that this is only slightly increased by dilution. He states that in its behavior it is more like a neutral salt than an acid. In I89I Marckwald $^{5}$ called attention to the fact that amino acids of the aliphatic series react only slowly with the mustard oils, while other primary amines react quite readily. Since the amino acids react easily in alkaline solutions, he held that the acids are, in reality, inner salts. Sakurai ${ }^{6}$ attempted to substantiate the "inner salt" structure on the preparation from halogen derivatives of the acids and on the resistance which amino acids offer to the formation of acid chlorides. Walker ${ }^{7}$ points out that conductivity determinations tell us very little about the structure of glycocoll but that since the conductivity of phenylglycocoll, $\mathrm{C}_{6} \mathrm{H}_{5} \mathrm{NHCH}_{2} \mathrm{CO}_{2} \mathrm{H}$, is greater than that of acetic acid it must contain a carboxyl group which ionizes. Tilden and Forster ${ }^{8}$ showed that the amino group of amino acids

2 "Zwitterion."

${ }^{3}$ Ann., I76, 349 (1875).

${ }^{4} J$. prakt. Chem., 32, 369 (I885).

${ }^{5}$ Ber., 24, 3278 (I89I).

${ }^{6}$ Proc. Chem. Soc., Io, No. 138 (I894).

${ }^{7}$ Proc. Chem. Soc., io, No. I39 (1895).

${ }^{8}$ Chem. Nerws, 7I, 239 (I895). 
may be replaced by chlorine by the action of nitrosyl chloride and considered this an argument against the inner salt formation. Somewhat later Carrara and Rossi ${ }^{9}$ based an argument for the inner salt structure on the conductivity of betaine hydrochloride, $\left(\mathrm{CH}_{3}\right)_{3} \mathrm{NClCH}_{2} \mathrm{CO}_{2} \mathrm{H}$. From the values found they considered that the salt was almost completely hydrolyzed to hydrochloric acid and betaine, $\left(\mathrm{CH}_{3}\right)_{3} \mathrm{NCH}_{2} \mathrm{CO}$. Winkelblech ${ }^{10}$ points out, however,<smiles>C1COC1</smiles>

that if betaine hydrochloride is in reality hydrolyzed the conductivity of the solution should be the same as that of the equivalent amount of hydrochloric acid while both Bredig's measurements and those of Carrara and Rossi gave a conductivity scarcely more than one half as great There can be no doubt, of course, that the anhydride of betaine, $\left(\mathrm{CH}_{3}\right)_{3} \mathrm{NCH}_{2} \mathrm{CO}_{2}$, has the structure of a salt, but no one seems to have determined whether this is monomolecular or dimolecular. Our results given below indicate that a solution of an amino acid which gives no inner salt may still contain the acid mostly in the monomolecular form.

Winkleblech ${ }^{11}$ discusses the hydrolysis of an amino acid on the basis of conductivity data for weak acids, weak bases and water. It does not seem possible from conductivity data, however, to determine whether the acid is in the form of an inner salt,

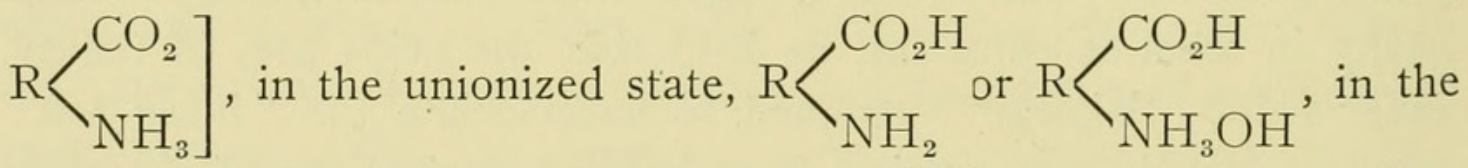
form of the double, amphoteric ion $\mathrm{R} / \mathrm{CO}_{2}^{-}$or in the form of a bimolecular salt, $\mathrm{R}\left\langle\begin{array}{l}\mathrm{CO}_{2}-\mathrm{NH}_{3} \\ \mathrm{NH}_{3}-\mathrm{CO}_{2}\end{array}\right\rangle \mathrm{R}$. The hydrogen and hydroxyl ions of the amphoteric form would, of course, combine to form water and if the acid and basic functions were of equal "strength" the solution would react neutral. None of these forms would show any conductivity and while the bimolecular form could be distin-

${ }_{9}$ Atti R. Accad. Lincei (5), 6, 208 (1897).

${ }^{10}$ Z. physit. Chem., 36, 590 (1901).

${ }^{11}$ Loc. cit. 
guished from the others by a determination of the molecular weight it is not clear how any of the ordinary physical methods could be used to distinguish between the three forms, $\mathrm{R}\left\langle\frac{\mathrm{NH}_{3}}{\mathrm{CO}_{2}}, \mathrm{R}\left\langle\mathrm{NH}_{3} \mathrm{OH}\right.\right.$ and $\mathrm{R}\left\langle\mathrm{NH}_{3}^{+}{ }^{\mathrm{CO}_{2}^{-}}\right.$. The form $\mathrm{R}\left\langle\mathrm{NH}_{2}\right.$ would have a lower molecular weight and might, possibly, be distinguished from the other three by that means. It does not seem to us that the ordinary equations for hydrolysis, which Winkelblech attempts to apply, could be used in a complex case of this sort.

From the above summary it would seem that the evidence with regard to inner salt formation is not altogether satisfactory and light upon the question from an entirely different point of view is welcome. We think that we have secured this from a study of the specific rotations of a series of amino acids derived from camphor. The formulas and names of the compounds are given below. To bring out the relationships more clearly the specific rotations given for the salts are calculated to the basis of one gram of the free acid in I c.c. of the solution instead of for one gram of the salt.

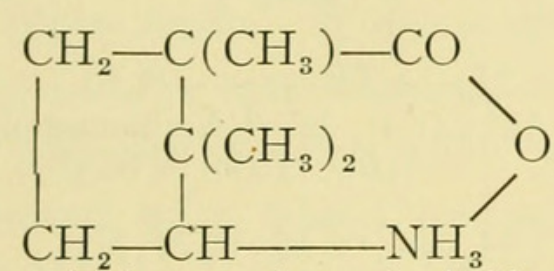

Aminocamphonanic Acid.

$(\alpha)_{D}=-29.2^{\circ}$.

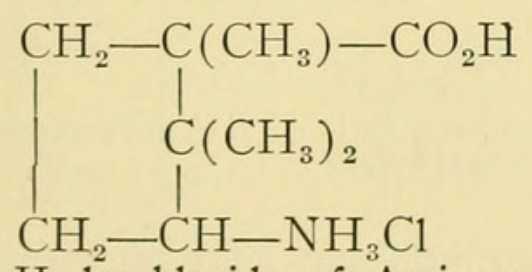

Hydrochloride of Aminocamphonanic Acid. $(\alpha)_{D}=25.0^{\circ}$.

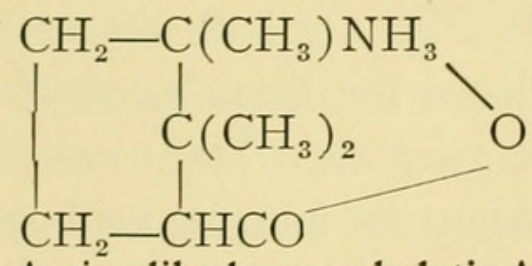

Aminodihydrocampholytic Acid. $(\alpha)_{D}=53.7^{\circ}$.

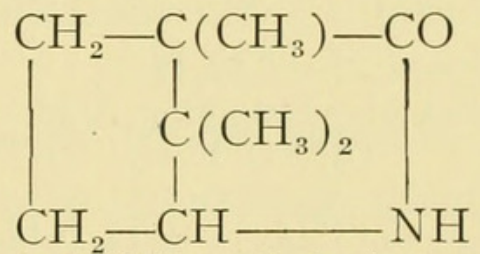

Anhydride of Aminocamphonanic Acid. $(\alpha)_{D}=-60.5^{\circ}$.

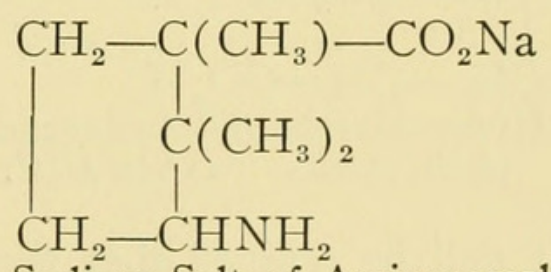

Sodium Salt of Aminocamphonanic Acid. $(\alpha)_{D}=52.8^{\circ}$.

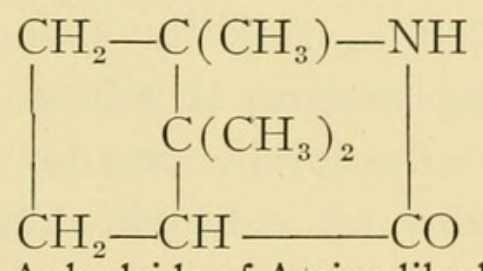

Anhydride of Aminodihydrocampholytic Acid. $(\alpha)_{D}=72.8^{\circ}$. 
<smiles>CC(C)(C)C(C(=O)O)C(C)(C)CN</smiles>

Hydrochloride of Aminodihydrocampholytic Acid. $(\alpha)_{D}=4 \mathrm{I} \cdot 3^{\circ}$.<smiles>CC(CN)C(CCC(=O)O)C(C)(O)CCC(=O)O</smiles>

$\alpha$-Aminocampholic Acid. $(\alpha)_{D}=67^{\circ}$.<smiles>CC(C)(CC(=O)O)C(CN)CCl</smiles>
Hydrochloride of $\alpha$-Aminocampholic Acid. $(\alpha)_{D}=44.7^{\circ}$.<smiles>CC(C)(CCN)C(CCCN)C(=O)O</smiles>

$\beta$-Aminocampholic Acid. $(\alpha)_{D}=\mathrm{I} 6.4^{\circ}$.<smiles>CC(C)C(C(=O)O)C(C)(C)C</smiles>

Hydrochloride of $\beta$-Aminocampholic Acid. $(\alpha)_{D}=41.3^{\circ}$.<smiles>CCCCC(C(N)=O)C(C)(C)N</smiles>

Sodium Salt of Aminodihydrocampholytic Acid. $(\alpha)_{D}=18.3^{\circ}$.<smiles>CC(=O)NCC1CCC1(C)C</smiles>

Anhydride of $\alpha$-Aminocampholic Acid. $(\alpha)_{D}=-33.9^{\circ}$.

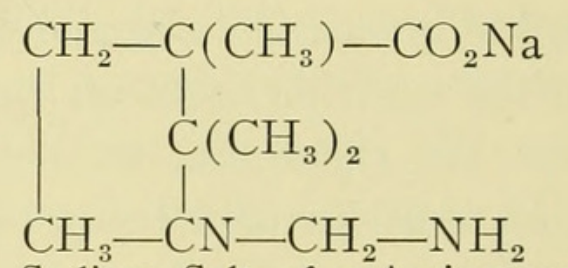

Sodium Salt of $\alpha$-Aminocampholic Acid. $\quad(\alpha)_{D}=62.4^{\circ}$.

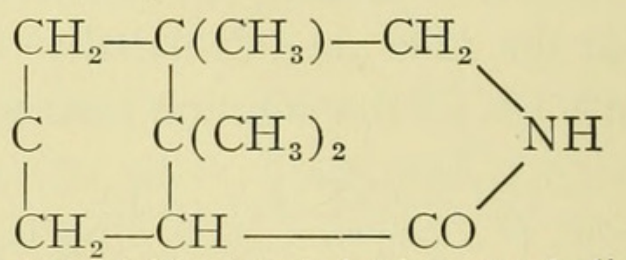

Anhydride of $\beta$-Aminocampholic Acid. $(\alpha)_{D}=66.5^{\circ}$.

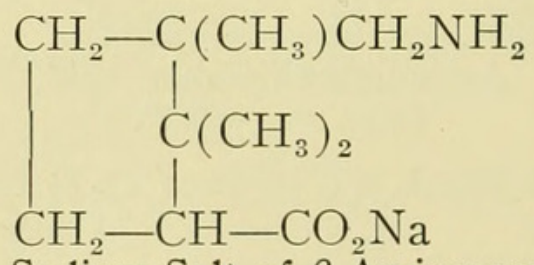

Sodium Salt of $\beta$-Aminocampholic Acid. $(\alpha)_{D}=\mathrm{I} 4.3^{\circ}$.

It will be noticed that the aminocamphonanic acid and aminodihydrocampholytic acid are represented as having a cyclic or inner salt structure, while the aminocampholic acids are both represented as having an open structure. The evidence for these structures is based on the specific rotations of the compounds. The rotation of the sodium salt and hydrochloride of aminocamphonanic acid are to the right while that of the anhydride, which is undoubtedly cyclic in 
structure, is to the left. The free acid is also left handed, indicating a cyclic structure similar to that of the anhydride. The sodium salt and hydrochloride of aminodihydrocampholytic acid are right handed. The free acid and anhydride are also right handed, but with a considerably increased rotation. The sodium salt and free $\alpha$-aminocampholic acid are both right handed with rotations closely alike, indicating that each has an open structure, but the anhydride, which certainly has a cyclic structure, is left handed and has a rotation very closely like that of the aminocamphonanic acid, indicating again very clearly that the latter has a cyclic structure and that each compound contains a cycle of six atoms. The sodium salt of $\beta$ aminocampholic acid and the free acid also correspond closely in rotation, indicating an open structure for both, while the hydrochloride and anhydride have a considerably greater rotation, as is the case with both the free aminodihydrocampholytic acid and its anhydride.

All of these observations are consistent with the hypothesis that aminodihydrocampholytic and aminocamphonanic acid form cyclic salts containing cycles of six atoms, while the aminocampholic acids do not form such salts because, if formed, they would contain cycles of seven atoms. It seems difficult to find any other simple explanation for the observations.

The results also point very strongly to the formula for ammonium salts which represents them as containing quinquivalent nitrogen and against Werner's formula. According to Werner's formula the free aminocamphonanic and aminodihydrocampholytic acids would contain cycles of seven atoms,

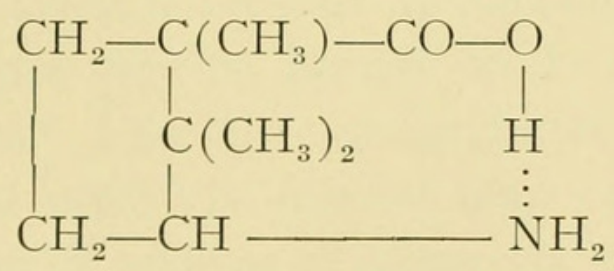

Such a formula is quite inconsistent with all that we know about the ease with which rings of five and six atoms are formed and the comparative rarity of seven-atom rings. It is also inconsistent with the close agreement between the rotation of the aminocamphonanic 
acid and that of the anhydride of $\alpha$-aminocampholic acid. We know that the latter compound contains a six-atom ring.

Determinations of the molecular weights in aqueous solutions by the freezing point method have shown that all four of the amino acids are monomolecular in such solutions.

The experimental details of the investigation will be published in the Journal of the American Chemical Society. 


\section{$2 \mathrm{BHL}$ Biodiversity Heritage Library}

Noyes, William A and Potter, Ralph S . 1914. "The Valence of Nitrogen in Ammonium Salts." Proceedings of the American Philosophical Society held at Philadelphia for promoting useful knowledge 53(213), 18-24.

View This Item Online: https://www.biodiversitylibrary.org/item/31934

Permalink: https://www.biodiversitylibrary.org/partpdf/212071

\section{Holding Institution}

Harvard University, Museum of Comparative Zoology, Ernst Mayr Library

\section{Sponsored by}

Harvard University, Museum of Comparative Zoology, Ernst Mayr Library

\section{Copyright \& Reuse}

Copyright Status: NOT_IN_COPYRIGHT

This document was created from content at the Biodiversity Heritage Library, the world's largest open access digital library for biodiversity literature and archives. Visit BHL at https://www.biodiversitylibrary.org. 